\title{
Access to improved sanitation facilities in low-income informal settlements of East African cities
}

\author{
K. Okurut ${ }^{1,2 *}$, R.N. Kulabako², J.M. Adogo ${ }^{3}$, J. Chenoweth ${ }^{1}$, S. Pedley ${ }^{4}$, A. Tsinda ${ }^{1}$, K. Charles ${ }^{5}$ \\ ${ }^{1}$ Centre for Environmental Strategy (CES), University of Surrey, Guildford, UK \\ ${ }^{2}$ Departments of Civil and Environmental Engineering-CEDAT, Makerere University, Kampala, Uganda \\ ${ }^{3}$ Schools of Law, University of Surrey, Guildford, UK \\ ${ }^{4}$ RCPEH, University of Surrey, Guildford, UK \\ ${ }^{5}$ School of Geography and the Environment, University of Oxford, OX1 $3 Q Y$ \\ *Email: k.okurut@surrey.ac.uk/okenan@cedat.mak.ac.ug
}

\begin{abstract}
Throughout Africa, the population in urban areas is increasing rapidly beyond the capacity and the resources of the cities to accommodate the people. In Sub-Saharan Africa, the majority of urban dwellers live in informal settlements served by inadequate sanitation facilities. These areas present unique challenges to the provision of sanitation, and there is inadequate information on access to improved facilities. This paper reports findings of a study undertaken in low-income informal settlements using mixed methods to assess access to sanitation and identify the barriers to household improved sanitation facilities. Although more than half $(59.7 \%)$ of the respondents reported using sanitation facilities that are included in the JMP definition of improved sanitation, a high proportion of these facilities did not provide " access to basic sanitation" and less than 5\% of all the respondents did not report issues related to sustainable access to basic sanitation. The findings highlight the urgent need to develop a more specific and strategic interventions for each low-income informal settlement, to upscale the sustainable access and use of improved sanitation in urban centres.
\end{abstract}

Key words: Access, Barriers, East Africa, Improved sanitation, Informal settlements, mixed methods.

\section{Introduction}

Provision of safe and adequate sanitation in informal settlements for improved health and sustainable livelihoods are challenging due to the social, environmental, economic, institutional and demographic characteristics (Isunju et al. 2011; Mara et al. 2010) that are unique for each settlement (Foppen \& Kansiime 2009; Katukiza et al. 2012). Due to the rapid population growth in urban areas of most of the developing countries, the vulnerable and marginalised end up settling in informal settlements where basic sanitation coverage is much lower compared to the average for urban areas (Foppen \& Kansiime 2009; Grimm et al. 2008). 
Throughout Africa, the rate of increase in the population is most often higher than the capacity, resources and services that the urban authorities can provide to address the sanitation challenges in urban areas (Kariuki 2011). Attempts to increase access to improved sanitation (as defined by the WHO/UNICEF Joint Monitoring Programme) (WHO/UNICEF 2012) in low-income informal settlements has yielded slow progress partly because of inadequate information on the sanitation situation in these area, where about $62 \%$ of urban dwellers live, in sub-Saharan African (UN-HABITAT 2011). It is generally reported that the most used form of sanitation in informal settlements are on-site sanitation that are often shared, and may not be adequate enough to provide dignity and privacy for the users (Katukiza, et al. 2012; Tumwebaze et al. 2013; Van Der Geest 2002). Beyond the use of onsite sanitation, there is insufficient information on what proportion is improved or adequate to provide full public health and socio-economic benefit to the users. The objective of this study was to determine the proportion of households in low-income informal settlements, with access to improved sanitation. It builds on the findings from a household survey, to report on access to improved sanitation in low-income informal settlements using mixed methods (Okurut et al. 2013; Tsinda et al. 2013). The use of on-site sanitation facilities that are not properly constructed and maintained, partly cause illness and the contamination of water sources (Isunju, et al. 2011; Nyenje et al. 2010).

Three East African cities of Kampala (Uganda), Kigali (Rwanda) and Kisumu (Kenya), have been used as case study cities in sub-Saharan Africa. Low-income informal settlements of the three cities have unique challenges to the provision of sanitation and causing some inhabitants to defecate in the open (Maoulidi 2010; Sano 2007; Tumwebaze, et al. 2013). The settlements are located on illegal land and/or have sub-standard structures in the urban context and often lying on hilly slopes (Kigali) or wetlands (Kampala) or black cotton soil (Kisumu) that are challenging for the construction of sanitation facilities. Although the WHO/UNICEF Joint Monitoring Programme (JMP) for water and sanitation reports that, in 2010, the three East African countries of Kenya, Rwanda and Uganda had urban sanitation coverage of 32\%, 52\% and 34\% respectively (WHO/UNICEF 2012), it does not point out the disparities in conditions within the formal and informal parts of the urban area. This gives an incorrect picture of the sanitation situation in the informal urban context.

It's therefore important to understand the real situation of improved sanitation coverage in informal settlements according to the definition developed by the Millennium Task Force as 
"access to, and use of excreta and wastewater facilities and services that ensure privacy and dignity, ensuring a clean and healthy living environment for all" (COHRE et al. 2008). This will inform policy makers of best approaches to improve access in low-income informal settlements as opposed to the conventional approaches in planning for formal urban areas. The conventional approaches of planning for sanitation that puts the emphasis on the supply of technologies to users does not address the needs of the end users (Hogrewe et al. 1993; Jenkins \& Scott 2007; Samanta \& Van Wijk 1998; Varley et al. 1996), and has not realised the much needed progress in informal settlements. To meet the sanitation needs of the end users sustainably, effort is required to understand the barriers to build an improved sanitation, in order to develop specific and appropriate strategies for addressing the situation in the local context.

\section{Methodology}

This study used mixed methods to assess access to improved sanitation facilities in lowincome informal settlements of three cities in East Africa. Mixed method research involves the use of both quantitative and qualitative approaches in tandem so that the overall strength of the study is greater than either qualitative or quantitative research alone (Creswell \& Clark 2007). The mixed methods included: diagnostic study, transect walks, household surveys, focus group discussions (FGDs) and interviews. A diagnostic study of the sanitation situation in the case study cities was conducted to understand what is known about the cities; upon which eight low-income informal settlements were purposively selected for the study. The three cities, and the settlements, were selected for their similarities and differences in the provision of sanitation facilities that exist in and between each. The study settlements selected have urban characteristics with high population densities and poor neighbourhoods, and have been reported to have sanitation related problems. The study sample size in each city was determined using a simplified sample size formula for proportions (Israel 1992). A stratified probability survey was used to administer questionnaires to household heads or adult members of approximately 5,500 households in the eight settlements of the three case study cities between May and September 2012. The study samples sizes for Kigali (1794), Kampala (1666) and Kisumu (1927) were based on the national statistics of the study settlements for the three cities, and allowed for comparative analysis of sub-groups (KNBS 2010; NISR 2008; UBOS 2011). 
The household samples for the surveys were selected through random route sampling techniques in proportion to the population of study area. Boundaries of the primary sample units (cells / zones / villages) in each study settlement were first identified with the help of the respective local authorities (guides) during transect walks through the settlements, to collect community information by observations and informal questioning. The researchers then randomly selected a number of routes with clearly identifiable physical features through the primary sample unit and, by walking along every route from the start to end; the $\mathrm{n}^{\text {th }}$ household was systematically selected to constitute the study sample. To ensure that every household in the settlement had an equal chance of being selected, 10 households were systematically selected along each random route and the number of random routes in each primary sample unit was determined as a proportion of the total sample required for the whole settlement.

Findings from the household survey was sequentially used to develop qualitative tools for more in-depth understanding (Johnson \& Onwuegbuzie 2004) of access to improved sanitation from the perspectives of tenants, owner occupiers, local authorities, community health workers, upper primary school pupils, persons with disability, and city officials. Samples for the qualitative study were purposively selected from participants who live, work or are involved in sanitation activities, with a target of having the most productive sample to discuss or answer the questions until new explanations stop emerging from the data. Interviews were conducted with representatives of groups where the minimum number of participants (6 - 12 persons) for a FGD could not be realised. The study conducted a total of 83 focus group discussions by gender, except for local authorities and 99 interviews: 23 FGDs and 28 interviews in Kampala, 26 FGDs and 28 interviews in Kigali and 34 FGDs and 43 interviews in Kampala between March and July 2013. The researcher facilitated discussions / interviews using FGD / interview guides for each city developed from key issues that came out of the household survey result for the respective city, in a language best understood by the group or individual, and later translated to English. The groups or individuals were engaged to express their views, and interesting points followed-up with prompts and probes, to get more in-depth understanding of access to improved sanitation. The survey questionnaire, FGD and interview guides were pilot tested before being administered in the communities, and all the staff involved with the data collection were familiar with the local languages and were trained before conducting the field work. 
Due to the difference in cost of living in the three countries and the very inaccurate income data, deprivation was used as a multidimensional scale to measure the poverty levels across the three cities. Variables on ability to afford basic needs were used to construct a deprivation index and then normalised to have distributions around the mean for samples as a whole and for each county. The variables on ability to afford basic foods, essential clothes, lighting, fuel for cooking and portable water (constantly, sometimes and never); where used to develop a multidimensional index for the level of deprivation for each household, relative to the deprivation scale of the city. The household was then classified as; very deprived, deprived or not deprived.

For a sanitation facility to provide full public health benefit, it must meet some acceptable conditions. The facility should be easily accessible, ensure privacy, dignity, cleanliness and a healthy environment for all (COHRE, et al. 2008). This research evaluated the conditions of each facility based on self-reported problems with usage that the user or household experiences with their existing sanitation facility. Smell, shared usage, difficult to clean, insects, fill quickly, costs of empting, blocks frequently, lacks privacy, cost of paying for usage (in case of public/community toilets), distance from dwelling, safety, not available when need to use and water ingression, are some of the common problems that can be associated with on-site sanitation systems in informal settlements (COHRE, et al. 2008; Katukiza, et al. 2012; Tumwebaze, et al. 2013). As the problems were self-reported, they are indicative of problems in the sanitation facilities and mean that systems might not be providing the full public health benefit. Therefore, only sanitation facilities of improved technology with no self-reported problems of any sort were considered acceptable by the user and were likely to offer sustainable access to provide full public health benefits.

Statistical Package for the Social Sciences (SPSS version 20) was used to analyse the household survey data for frequencies, rates and proportions; and cross tabulations were carried out to examine relationships between variables. Pearson Chi-Square values were used to determine the strength of relationship between variables at a 95\% significant level. The survey and the methodology were given a favourable response from the Ethics Committee at the University of Surrey.

\section{Results and discussions}

\section{The settlements}


From the diagnostic study and observations made during the transect walks and household survey in the eight study sites, the settlements were found to have the conditions that define informal urban areas. The settlements are either located on illegal land and/or are unplanned with congested housing structures that are not in compliance with the city council standards, and present varied challenges in the provision of improved sanitation. The houses, mainly of single-roomed households, were made of mad/burnt clay bricks/sheet/stone walls with tin/corrugated iron sheets and occasionally cemented floors. The two settlements of Gatsata and Kimisagara in Kigali are suited on hill slopes with rocky grounds, and valley floor with high water table respectively, making it difficult to dig pit latrines, while the valley floors are also prone to flooding. The three settlements in Kampala: Bwaise III, Namuwongo-Soweto and Kisenyi II are low-lying areas, mostly reclaimed wet-lands with a high water table and prone to flooding. The communities of Manyatta B, Nyalenda B and Obunga settlements in Kisumu have low-lying black cotton soil and are rocky in a few places, with a high ground water table that occasionally floods. These conditions were also described by residents during a focus group discussion:

"Soil conditions are very poor and easily destroyed by rainfall. During dry seasons its better but during rainy seasons, there is a lot of floods in the area leading to many diseases", Focus group discussion, male owner occupiers, Kisumu.

The household survey results indicate that low-income informal settlements of the three cities have different demographic characteristics that vary in both social and economic aspects. The majority of respondents (61.3\%) were female; with the highest in Kigali (66.2\%) and lowest in Kisumu (54.6\%) while in Kampala it was 63.7\%. About half of the respondents $(44.7 \%)$ were aged between 25-35 years, while the proportions of respondents in the age groups 16-24 and over 36 years were almost equal, $26.9 \%$ and $26.5 \%$ respectively. The settlements in Kisumu have high proportions of tenants (a) and deprived households (b) compared to the settlements in Kigali and Kampala, as shown in Figure 1.

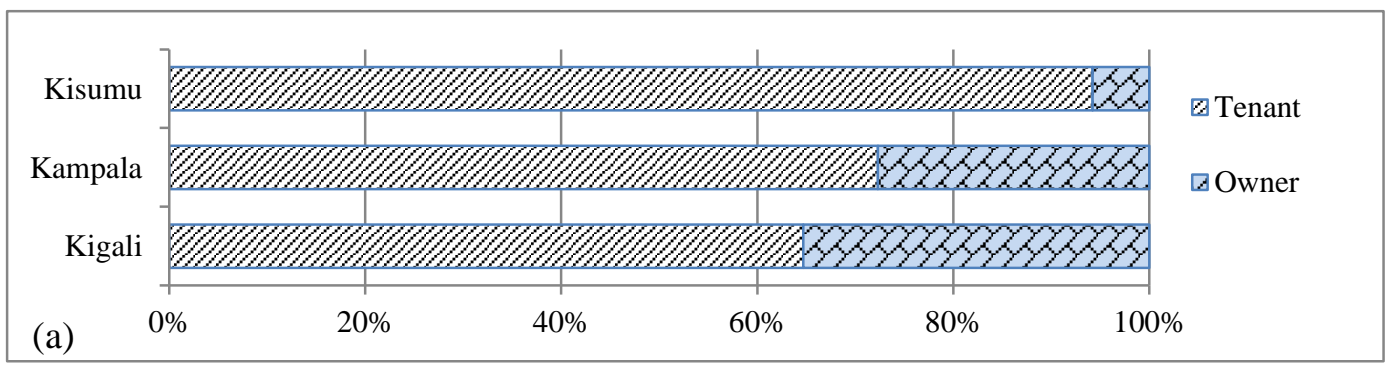




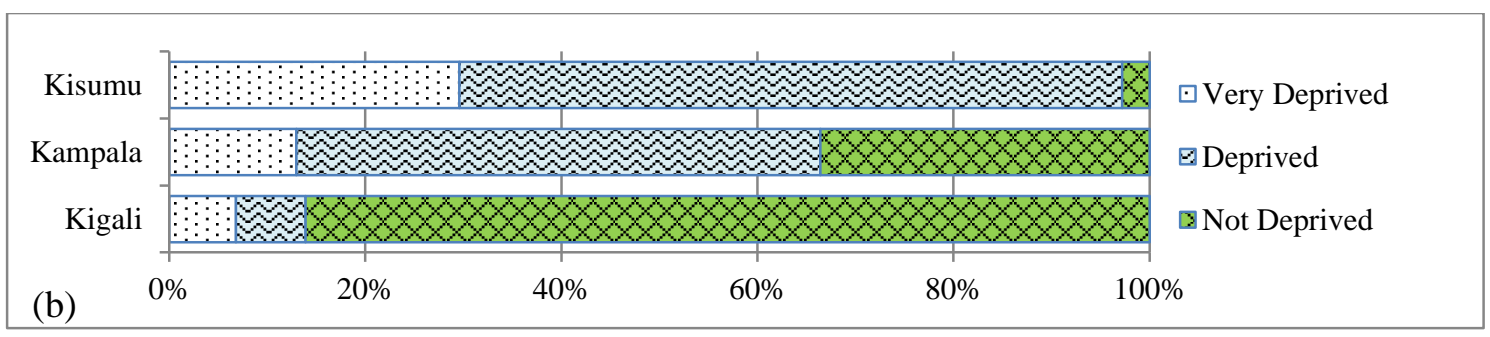

Figure 1: Proportion of tenant (a) and deprived (b) households

With regard to the education level of the respondents, the household survey showed that the majority were educated up to primary/secondary level, the highest in Kisumu; though Kampala reported the highest proportion of respondents with higher education level, see Figure 2.

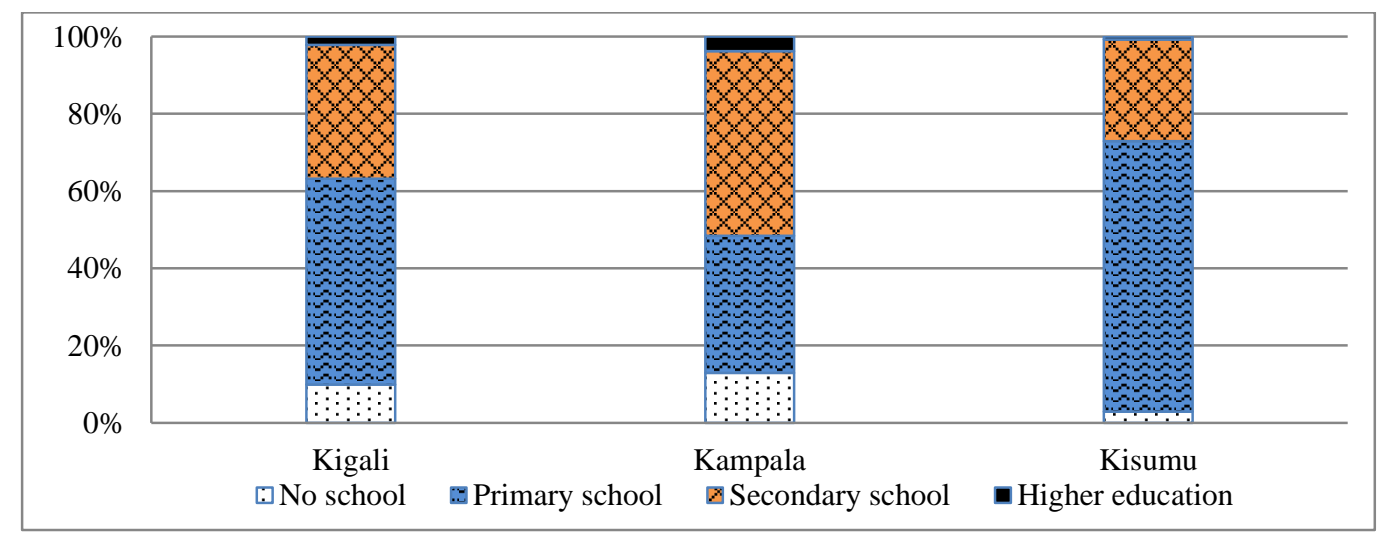

Figure 2: Education level of respondents

It is theorised that both geophysical characteristics of an area and the socio-economic characteristics of households influence the type of sanitation facility used at a household level (Hogrewe, et al. 1993). Before a household decides to install an improved sanitation facility, a number of factors influence the decision process; from preference, through to intent, to finally making a choice to adopt to a better facility (Jenkins \& Scott 2007). This means that the different levels of sanitation coverage in the three case study cities may, to some extent, be explained by the differences in demographic characteristics of the cities.

\section{Sanitation facilities}

This paper considers improved sanitation technologies to include: Flush toilet connected to sewerage system/septic tank, ventilated improved latrine (VIP), pit latrine with a slab, composting toilet and Urine Diverting Dry Toilet (UDDT).

The household survey reveals that there are appropriate facilities being built, generally in low-income informal settlements of the three cities, with about $77.4 \%$ of privately owned 
facilities being of improved sanitation technologies. However, more than half of the improved technologies were self-reported to have problems. The self-reported problems with existing improved technologies significantly $(\mathrm{p}<0.0005)$ varied between the cities but were mainly related to shared usage (65.5\%), smell (54.0\%) and insects (46.9\%). Other problems were: safety (45.0\%), cleanliness (39.4\%), lacks privacy (34.9\%), fills quickly (29.9\%), water ingresses (26.4\%), distant from dwelling (24.2\%), not available when needed (22.4\%), blocks frequently $(15.9 \%)$, and cost of emptying $(15.0 \%)$. The reported problems with the existing facilities point to inadequacy of the facilities to provide full public health and socio-economic benefits to the users and renders them unimproved (COHRE 2008; De Bruijne et al. 2007). Considering improved sanitation technologies with no reported problems, less $5 \%$ of the facilities in the study sample meet the conditions required for improved sanitation facilities, Table 1. From observations, it was also noted that the majority of the facilities had no hand washing amenities for hygienic purposes.

Table 1: Category of sanitation facilities reported by respondents

\begin{tabular}{|l|l|l|l|l|l|}
\hline \multicolumn{2}{|c|}{ Household sanitation system } & $\begin{array}{l}\text { Kigali } \\
(\%)\end{array}$ & $\begin{array}{l}\text { Kampala } \\
(\%)\end{array}$ & $\begin{array}{l}\text { Kisumu } \\
(\%)\end{array}$ & $\begin{array}{l}\text { Total } \\
(\%)\end{array}$ \\
\hline \multirow{2}{*}{$\begin{array}{l}\text { General } \\
\text { classification by } \\
\text { technology type }\end{array}$} & Open defecation & 0.3 & 0.2 & 17.3 & 6.3 \\
\cline { 2 - 6 } & Unimproved technology & 43.5 & 42.9 & 17.3 & 59.7 \\
\cline { 2 - 6 } & Improved technology & 56.2 & 56.9 & 65.4 & 33.9 \\
\hline \multirow{2}{*}{$\begin{array}{l}\text { Private and no } \\
\text { problem with } \\
\text { usage }\end{array}$} & Private facilities & 26.7 & 11.7 & 1.2 & 13.7 \\
\cline { 2 - 6 } & Private improved technology & 18.3 & 11.3 & 0.8 & 9.9 \\
\cline { 2 - 6 } & $\begin{array}{l}\text { Private improved technology } \\
\text { having no self-reported problems }\end{array}$ & 7.5 & 6.1 & 0.1 & 4.4 \\
\hline
\end{tabular}

The results of this study compares with finding reported from other studies. The household survey results on open defecation (Table 1), compares with the figures reported for the same cities in other studies: less than $1 \%$ in Kampala slums, $17.5 \%$ in Kisumu and about $1.0 \%$ in peri-urban Kigali (Maoulidi 2010; OZarchitecture 2007; Tumwebaze, et al. 2013). Though the same studies also reported on access to sanitation facilities as $20.4 \%$ private sanitation facilities in Kampala, 82.2\% improved facilities in Kisumu, and about 83.0\% private facilities in Kigali; the figures are high compared to the findings from this study (Table 1). Despite the three studies generalizing informal settlements in each of the three cities, they give no information on the conditions of the improved technologies. Many scholars have urged that, it is possible to have an improved sanitation technology, but not used due to un desired conditions or where the user demands are not meet (Mara, et al. 2010; Okurut et al. 2014; 
Peal et al. 2010). The findings on access to improved sanitation facilities with no selfreported problems, in this study, give a better picture of the situation in low-income informal settlements. The household survey findings on access to improved sanitation facilities were also supported by the views of the participants in the majority of the focus group discussions:

"Most of the households here don't have what fits to be a toilet. Some are far away especially those who use public toilets do not go there at night and so opt to use polythene bags and dump them into the open. Due to the bad toilets, some children fall sick. Cholera and other disease outbreaks have been reported in these settlements", Focus group discussions, female tenants, Kampala.

From the household survey, Kisumu has lots of improved sanitation technologies but also had the highest numbers of households sharing (6.8 \pm 1.7$)$ compared to Kigali $(4.3 \pm 2.4)$ and Kampala (6.3 \pm 1.6$)$ per stance. Tumwebaze et al. (2014) reported that hygienic maintenance of shared toilets in urban slums is usually a challenge; which can partly explain why many improved technologies but very few of acceptable and adequate conditions for full benefits in Kisumu; resulting in high rate of open defecation. Discussions with upper primary school pupils in Kisumu revealed that people cannot use toilets that have been dirtied by nonmembers of their households. Conflict can accrue from sharing of toilets especially among tenants:

"We usually disagree especially in cleaning among ourselves, some people do not want to clean and the landlords are absent. We even try to identify the faeces by asking what diet one had last meal to be able to tell who has defecated on the side. You can hear someone saying "for us we ate 'embuta' (Nile perch), so this faeces cannot be for some body from our house”, Focus group discussion, female tenant, Kampala.

The existing situation highlights more concerns in Kisumu compared to the other two cities. To explain the trend of improved sanitation facilities requires an understanding of "who has improved technology?" by relating access to the demographic characteristic of the households.

\section{Distribution of sanitation technologies among the different households}

The household survey reveals that the likelihoods of an owner occupier or tenant having improved sanitation technologies are almost the same, however a higher proportion of tenants 
practice open defecation than owner occupiers. This finding highlights further that property ownership can influence one's defecation practice, which may be one of the reasons for low coverage in informal settlements, where the majority of the inhabitants are tenants. The reason is further supported by the arguments given by Miah and Weber (1991), that because tenants have stronger ties with their rural origin where they are likely to return and remit a significant portion of their income, they tend to give little priority to invest in improved sanitation facilities in the city. It is also noted that, for households where members had higher level of education, open defecation was not reported. The trend of sanitation type with education shows that the likelihood of practicing open defecation reduces with increasing level of education, as shown in Figure 3.
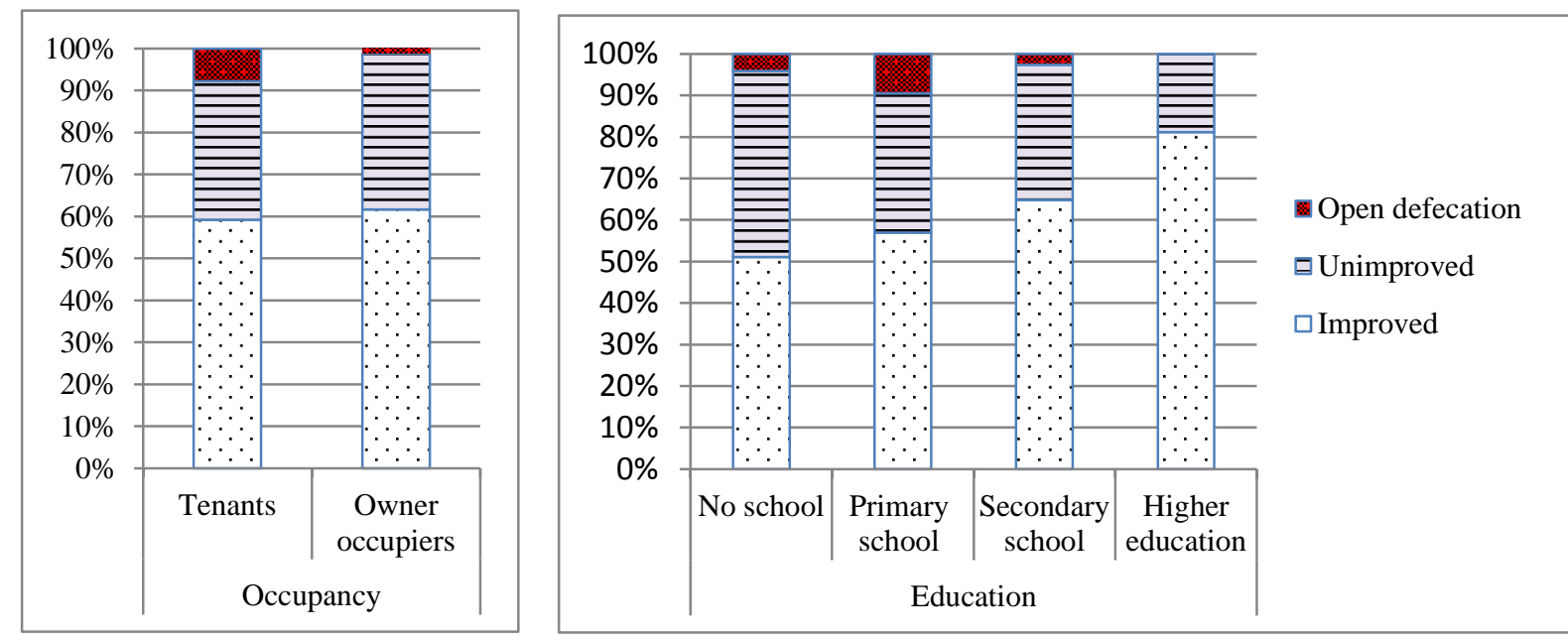

Figure 3: Comparison of sanitation type with occupancy status and education level of respondent

Considering only households with improved technologies, the household survey results show significant variation across the three cities with Kampala, reporting the highest proportion of owner occupiers with improved technologies. The proportions of households with improved technologies increase with increase in level of education across the cities, except in Kisumu (Table 2) where there was no consistent trend.

Table 2: Comparison of households using improved sanitation technologies with occupancy status and levels of education

\begin{tabular}{|l|l|c|c|c|c|c|c|c|}
\hline Variable & \multicolumn{2}{|c|}{ Kigali } & \multicolumn{2}{c|}{ Kampala } & \multicolumn{2}{c|}{ Kisumu } & $\chi^{2} \mathrm{p}$ value \\
\hline \multirow{3}{*}{ Improved technologies } & $\mathrm{N}$ & $\%$ & $\mathrm{~N}$ & $\%$ & $\mathrm{~N}$ & $\%$ & \\
\cline { 2 - 10 } & 1009 & 56.2 & 948 & 56.9 & 1260 & 65.4 & $<0.0005$ \\
\hline \multirow{2}{*}{ Occupancy } & Owner occupiers & 351 & 55.5 & 331 & 71.8 & 61 & 54.5 & $<0.0005$ \\
\cline { 2 - 9 } & Tenants & 658 & 56.7 & 617 & 51.2 & 1199 & 66.1 & $<0.0005$ \\
\hline \multirow{3}{*}{ Education } & No school & 85 & 47.8 & 104 & 49.5 & 38 & 67.9 & $<0.0005$ \\
\cline { 2 - 9 } & Primary school & 508 & 53.1 & 297 & 51.3 & 838 & 62.1 & $<0.0005$ \\
\cline { 2 - 9 } & Secondary school & 386 & 62.4 & 474 & 60.8 & 375 & 74.1 & $<0.0005$ \\
\hline
\end{tabular}




\begin{tabular}{|l|l|l|l|l|l|l|l|l|}
\hline & Higher education & 30 & 75.0 & 56 & 90.3 & 9 & 60.0 & 0.12 \\
\hline
\end{tabular}

The findings suggest that formal education exposes households to information and knowledge about good sanitation, and encouraging people to go to school can be one way of improving access to sanitation in low-income informal settlements. Property owners need to provide some rules and guidelines on hygienic defecation practice for their tenants.

\section{Reasons for lacking access to improved sanitation}

With regard to the reasons why households lack a private sanitation facility, the household survey shows that the majority of respondents who practiced open defecation in Kisumu reported either lack of space $(42.0 \%)$ or inability to afford $(39.3 \%)$ as the main reason for lacking a private sanitation facility. In another study conducted in Ghana to assess household demand for improved sanitations in rural and peri-urban areas, the authors also found that many respondents cited space $(48.4 \%)$ and high cost $(33.6 \%)$ as the constraints to constructing toilets (Jenkins \& Scott 2007).

Though lack of space was considered a major barrier among the open defecators, some areas in the settlements in Kisumu were not too congested, as observed during transect walks and household surveys. Pit latrines that get full were manually emptied and the content poured into shallow excavations within the courtyard. This was supported by responses of a group of 99 owner occupiers in the same survey, who indicated lack of money (75.8\%) and topography $(16.2 \%)$. Only $6.1 \%$ reported lack of enough space as a significant barrier faced in building a household sanitation facility, see Figure 5.

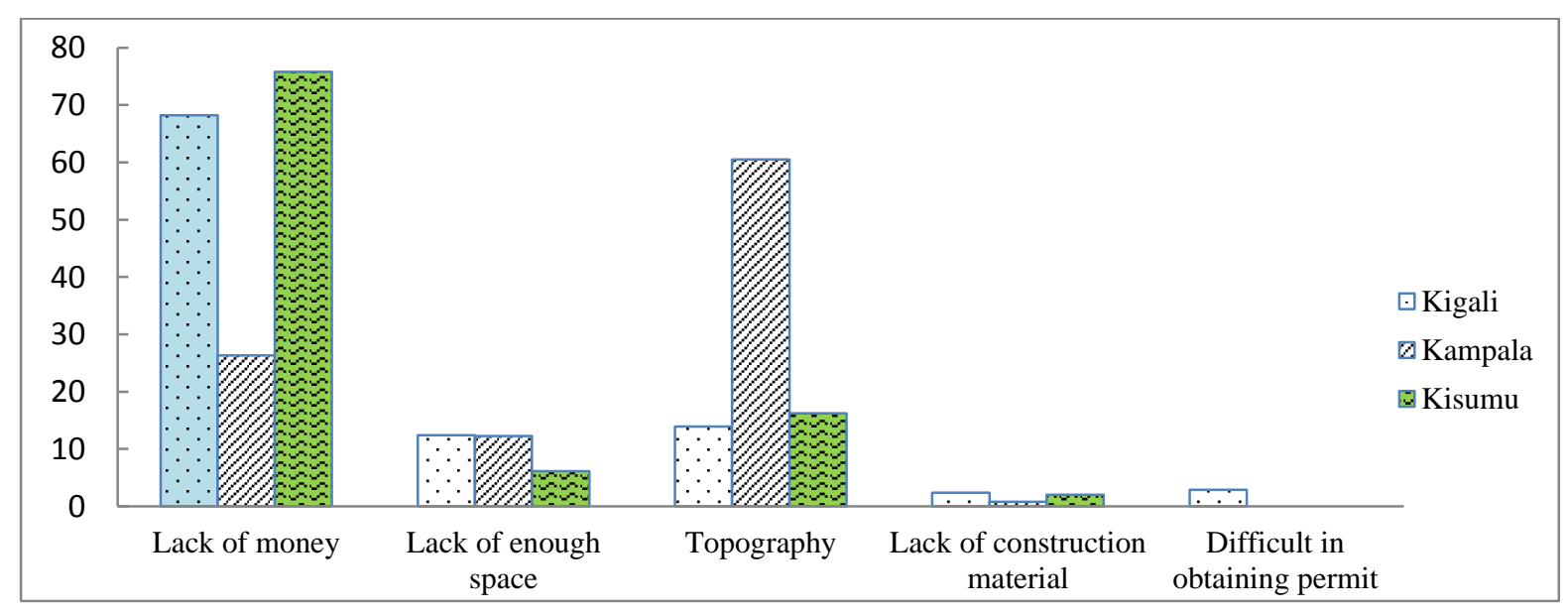

Figure 5: Most important barriers to build a toilet for own occupiers 
In the focus group discussions with local authorities in Kampala, the participants gave slightly different views from what the survey revealed. Though they ranked finance, topography (high water table) and high population as the major barriers in the order, they also mentioned culture as one of the hindrances to people using toilets and the poor attitude of landlords towards the welfare of their tenants and conditions surrounding their houses:

"We have people from different countries coming with different cultures and there is open defecation; you do not expect such people to behave like us; for example instead of coming to the toilet someone defecates on the railway line and also in polythene bags (buveera). This is the system; even old people use polythene bags. A person during the daylight can use a polythene bag and throw it on the roof of the neighbour”, Focus group discussions, local council authority (LC), Kampala.

Another local council member said: "Like when you have a visitor and the toilets are closed at night, this is a shortcut we always use. For example yesterday we were seated here with the chairman and a journalist, a man appeared at this public toilet, the people were using it and this drunken man stood there; in a few seconds we saw faeces dropping down the man's trousers as he was waiting to go in the toilet; people saw this".

From the household survey, a reasonable proportion in Kigali also reported no emptying service providers $(6.7 \%)$ compared to less than $1 \%$ in the other cities. Almost all the households in Kigali settlements $(99.0 \%)$ do not empty their toilet. This was also captured during a key informant interview with a health and sanitation officer in Kigali:

"Instead of emptying toilets, people pour excreta in the swamps or in the trenches off the main roads and others just close off the toilets and dig up new ones; they cannot afford the emptying services. The challenges to providing good sanitation are that houses are congested and accessibility to their homes is difficult and mind-sets of people. People do not want to change their lifestyles", Interview, City official, Kigali.

Even where households use an organic solution (11.8\%), which is a microbial technology used to decompose and supress the sludge and create more space in the toilet for further use in Kigali, at some point the toilet fills up.

The study shows that the cities have varied challenges in providing improved household sanitation and will require specific interventions for each city. For instance, the many 
unimproved technologies in Kigali could be linked to the lack of service providers coupled with the fact that the settlements have the highest proportion of squatters $(24.0 \%)$ and eviction notices $(9.5 \%)$ in the study cities, and thus cannot invest in better technologies. This will require opening up the market for sanitation services, and reforms on the land tenancy system in low-income informal settlements.

The results of the survey highlight the low level of access to improved sanitation and unhygienic human waste disposal practices in low-income informal settlements of these cities which pose a risk health to the lives of the community and a burden to urban authorities.

"In this area, we use spring water which comes from underground. In case there is a heavy down pour, the water changes colour, yet that is the only source of water for all purposes in this area. We do not know exactly what causes that. Toilets in this place are emptied into the drainage channel; sometimes it happens during the day and it creates foul smell in the area", Focus group discussion, male tenants, Kampala.

In Kigali, a male tenant also expressed the risks and challenges of poor sanitation practices:

"There are still some people who discharge faecal matter in the drainage channels mainly during the night when they are not seen and this happens when their toilets are full and they do not have any other space to dig another one. Waste can be seen at the sides of the streams and the accumulation of these attracts insects and flies, which causes diarrhoea to some children playing around and bad smell in the surroundings. Some toilets do not have privacy thus women and girls become uncomfortable using them", Focus group discussion, male tenants, Kigali.

The effect of poor sanitation from a single household can result into contamination of water sources used by the community, causing diseases, high costs on water treatment and many other unnecessary expenses for both individual households and urban authorities.

\section{Conclusion and recommendations}

Though some improved sanitation technologies can be found in low-income informal settlements, majority have inadequate conditions to provide full public health and socioeconomic benefits to the users. Shared usage, smell, insects, safety, cleanliness and lacks of privacy, are the top six conditions that render them unimproved. The barriers to access 
improved sanitation vary between cities and thus require specific interventions for each city: Kigali has many unimproved technologies and needs education on appropriate technologies and opening up the market for sanitation service providers like constructors and emptiers; Kampala has many public toilets that are constructed far from their user households due to space and topographical problems and need development of appropriate technologies for the settlements; while Kisumu has the highest proportion of deprived and improved technologies but with highest number sharing and unhygienically emptied, high levels of open defecation and hence the need for social interventions.

The findings imply that the unhygienic human waste disposal practices in low-income informal settlements pose a risk to the health of inhabitants in and around the settlements, quality of water sources and a burden to urban authorities. As a result, households are unnecessarily spending time and costs to treat or attend to family members who are sick of sanitation related illness. Governments are directly and indirectly spending lots of resources on medicine, water treatment as a result of contaminated sources, restoring the ecosystem lost by contamination, and many other costs. The situation highlights an urgent need to develop specific strategies that will improve sanitation conditions in each low-income informal settlement or city based on its unique characteristics and challenges. Efforts to increase sustainable access and use of improved sanitation in urban centres should give special attention to the population in low-income informal settlements and understand the specific unique challenges for appropriate solutions.

\section{Acknowledgement}

This study forms part of the 3K-SAN project funded by European Union under the SPLASH Sanitation programme. The authors would like to thank the contributions of the project team; P. Abbott, T. Kaime, R. Malcolm and L. Okotto; in the study design and the research assistants who were involved in the collection and entry of data in the three cities; Y. Karuhanga, L. Ninsiima, C. Tuyishime, G. Ngoboka, E. Munyeman, D. Onyango and M. Wayumba.

\section{References}

COHRE, WaterAid, and, S., \& UN-HABITAT. 2008 Sanitation: A human rights imperative (pp. 50). Geneva.

Creswell, J. W., \& Clark, V. L. P. 2007 Designing and conducting mixed methods research: Wiley Online Library.

Foppen, J. W., \& Kansiime, F. 2009 SCUSA: integrated approaches and strategies to address the sanitation crisis in unsewered slum areas in African mega-cities. Reviews in Environmental Science and Biotechnology, 8(4), 305-311. 
Grimm, N. B., Faeth, S. H., Golubiewski, N. E., Redman, C. L., Wu, J., Bai, X., \& Briggs, J. M. 2008 Global change and the ecology of cities. Science, 319(5864), 756-760.

Hogrewe, W., Joyce, S. D., \& Perez, E. A. 1993 Unique challenges of improving peri-urban sanitation: US Agency for International Development.

Israel, G. D. 1992 Determining sample size: University of Florida Cooperative Extension Service, Institute of Food and Agriculture Sciences, EDIS.

Isunju, J., Schwartz, K., Schouten, M., Johnson, W., \& Van Dijk, M. 2011 Socio-economic aspects of improved sanitation in slums: A review. Public Health, 125, 368-376.

Jenkins, M. W., \& Scott, B. 2007 Behavioral indicators of household decision-making and demand for sanitation and potential gains from social marketing in Ghana. Social Science \& Medicine, 64(12), 2427-2442.

Johnson, R. B., \& Onwuegbuzie, A. J. 2004 Mixed methods research: A research paradigm whose time has come. Educational researcher, 33(7), 14-26.

Kariuki, P. 2011 The challenges of financing sanitation in sub-saharan countries African: Acritical perspective. Journal of Applied Technology in Environmental Sanitation, 1(1), 9-16.

Katukiza, A., Ronteltap, M., Niwagaba, C., Foppen, J., Kansiime, F., \& Lens, P. 2012 Sustainable sanitation technology options for urban slums. Biotechnology advances.

KNBS. 2010. Population and Housing Census 2009 A, B, C and VII. Nairobi: Government printers.

Maoulidi, M. 2010 A Water and Sanitation Needs Assessment for Kisumu City, Kenya.

Mara, D., Lane, J., Scott, B., \& Trouba, D. 2010 Sanitation and health. PLoS medicine, 7(11), e1000363.

Miah, A. Q., \& Weber, K. E. 1991 Slum dwellers' household consumption pattern and its implication for cost recovery in slum upgrading: Evidence from Dhaka, Bangladesh. Review of Urban \& Regional Development Studies, 3(2), 170-182.

NISR. 2008 District Baseline Statistics: Gasabo and Nyarugenge Disticts. Kigali: Nationla Institute of Statistics for Rwanda (NISR).

Nyenje, P., Foppen, J., Uhlenbrook, S., Kulabako, R., \& Muwanga, A. 2010 Eutrophication and nutrient release in urban areas of sub-Saharan Africa--a review. Science of the total environment, 408(3), 447-455.

Okurut, Kulabako, R., Adogo, J. M., Chenoweth, J., Pedley, S., Tsinda, A., \& Charles, K. 2013 Improved sanitation in low-income informal settlements - Acase of East African cities: Is it amyth? Paper presented at the Water and Health Conference: Where Science meet Policy, UNC - Chapel Hill, USA.

Okurut, Kulabako, R. N., Chenoweth, J., \& Charles, K. 2014 Assessing demand for improved sustainable sanitation in low-income informal settlements of urban areas: a critical review. International Journal of Environmental Health Research(ahead-of-print), 1-15.

OZarchitecture, S. e. a. 2007 Kigali Conceptual Masterplan - Existing Conditions Analysis. Kigali: OZarchitecture.

Peal, A., Evans, B., \& van der Voorden, C. 2010 Hygiene and Sanitation Software: An Overview of Approaches (pp. 157). Geneva, Switzerland: Water Supply \& Sanitation Collaborative Council.

Samanta, B., \& Van Wijk, C. 1998 Criteria for successful sanitation programmes in low income countries. Health policy and planning, 13(1), 78-86.

Sano, J. C. 2007 Urban environmental infrastructure in Kigali city, Rwanda. Challenges and opportunities for modernised decentralised sanitation systems in poor neighbourhoods. M. Sc. thesis, Wageningen University, Wageningen.

Tsinda, A., Abbott, P., Pedley, S., Charles, K., Adogo, J. M., Okurut, K., \& Chenoweth, J. 2013 Challenges to Achieving Sustainable Sanitation in Informal Settlements of Kigali, Rwanda. International Journal of Environmental Research and Public Health(10), 6939-6954. doi: 10.3390/ijerph10126939

Tumwebaze, Orach, C. G., Niwagaba, C., Luthi, C., \& Mosler, H.-J. 2013 Sanitation facilities in Kampala slums, Uganda: users' satisfaction and determinant factors. International Journal of Environmental Health Research, 23(3), 191-204.

Tumwebaze, I. K., Niwagaba, C. B., Günther, I., \& Mosler, H.-J. 2014 Determinants of households' cleaning intention for shared toilets: Case of 50 slums in Kampala, Uganda. Habitat International, 41, 108-113. 
UBOS. 2011. 2011 Statistical Abstract. Kampala.

UN-HABITAT. 2011 State of the World's cities 2010/2011: Bridging the urban divide. London: UNHABITAT.

Van Der Geest, S. 2002 The night-soil collector: Bucket latrines in Ghana. Postcolonial Studies: Culture, Politics, Economy, 5(2), 197-206.

Varley, R. C. G., Yacoob, M. M., \& Smith, S. 1996 Beyond participation: locally based demand for environmental health in peri-urban areas: Environmental Health Project.

WHO/UNICEF. 2012 Progress on Drinking Water and Sanitation. In WHO/UNICEF (Ed.), The WHO/UNICEF Joint Monitoring Programme for Water Supply and Sanitation. New York: JMP. 